\title{
Simulation Based Endotracheal Intubation Education for Residents of Pediatrics
}

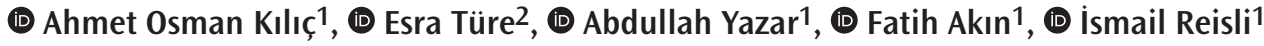 \\ 1Department of Pediatrics, Necmettin Erbakan University Meram Medical Faculty, Konya, Turkey \\ ${ }^{2}$ Clinic of Pediatric Emergency Medicine, Bursa City Hospital, Bursa, Turkey
}

\begin{abstract}
Aim: Endotracheal intubation is an important element of cardiopulmonary resuscitation. Gaining adequate experience with endotracheal intubation during pediatric residency is important. Our clinic initiated a simulation-based endotracheal intubation training for pediatric residents. This study aimed to evaluate the success of our endotracheal intubation training.

Materials and Methods: Residents received two programs of the simulation-based endotracheal intubation training at 1 year apart. Success rates were compared in terms of endotracheal intubation performance.

Results: Intubation success rates after the first and second programs were 80\% (28/35) and 100\% (35/35), respectively, and the difference was significant $\left(\chi^{2}=7.667, p=0.006\right)$. The mean durations of successful endotracheal intubation in both programs were $14.14 \pm 4.16$ sec and $8.22 \pm 3.58 \mathrm{sec}$, respectively. Intubation durations in the second program were significantly lower than those of the first $(p<0.01)$.

Conclusion: In this study, the simulation based-endotracheal intubation training, which was performed 1 year apart using high-fidelity manikins, increased the success rate of endotracheal intubation attempts and shorten the intubation time.
\end{abstract}

Keywords: Simulation, education, endotracheal intubation, pediatric residents, manikins

\section{Introduction}

Endotracheal intubation is one of the important steps of cardiopulmonary resuscitation (1). It is necessary to have an adequate experience for endotracheal intubation during pediatric residency, since the anatomy of the respiratory tract of children is different from adults and the majority of pediatric cardiopulmonary arrests are due to respiratory failure. Therefore, the curriculum of a pediatric residency includes endotracheal intubation training both theoretically and practically (2).

The need for endotracheal intubation is decreasing day by day due to the increase in the quality of health services and the development of non-invasive respiratory support facilities. Practical education cannot be provided adequately during the residency due to ethical problems, decreased intubation requirement, and increase in the number of residents (3).

Simulation based education (SBE) may play an important role to overcome this inadequacy. SBE is used in endotracheal intubation training because it creates a safe environment for acquiring technical skills, and the procedure can be repeated many times without the concern of harming the patient (4). In our clinic, simulation based endotracheal intubation educations are given regularly by using high fidelity simulators in a course program by faculty members of department of pediatrics.

In this study, we aimed to evaluate the success of this training program by comparing the results of two consecutive training sessions made with the same residents in terms of endotracheal intubation performance. 


\section{Materials and Methods}

The study included 35 residents who participated in simulationbased endotracheal intubation training at a tertiary university hospital. Endotracheal intubation education was prepared in accordance with the standards stipulated by the faculty education program. Program starts with a didactic lesson in which endotracheal intubation indications, types and steps of intubation are explained. After this theoretical briefing the participants are watched a real endotracheal intubation video made with a videolaryngoscope. At the end of the course, endotracheal intubation was performed practically on a highreality simulator manikin under the supervision of a faculty member of department of pediatrics.

In this study, practical endotracheal intubation education was performed on a high-fidelity manikin (VEVOR PVC intubation manikin ${ }^{\circledR}$ ), which is capable of simulating trachea, esophagus, lungs and stomach, and warns with sound when appropriate intubation is performed. The time between handling the blade of laryngoscope and inserting the intubation tube was measured. The American Academy of Pediatrics has reported that successful endotracheal intubation should be completed in less than 20 seconds (5). Accordingly, successful intubation criteria were accepted as placing the tube in the appropriate position in the trachea, completing the procedure before 20 seconds, and ventilating both lungs equally. If the first attempt was not successful, the manikin was ventilated with a balloon mask. Failure criteria were determined as intubation of the esophagus and ventilation of single lung. The same training process and measurements were made to all pediatric residents after one-year interval. All participants were given feedback after intubation attempts. Practical training was led by three faculty members of department of pediatrics. The results of the training were evaluated by the same people.

\section{Statistical Analysis}

Statistical analyses were performed with Statistical Package for the Social Sciences (SPSS, Ver 20) package program. Data were presented as mean \pm standard deviation and percentile. Paired sample t-test was used to compare intubation procedure times, chi-square test for comparison of success rates, one-way ANOVA test was used to compare success rates and intubation times with the duration of residency. P-value $<0.05$ was taken for statistical significance.

\section{Results}

The study included 52 pediatric residents in the first program and 58 in the second. The number of residents attending to both programs was 35 . We compared results of these 35 participants. Of the 35 participants, 20 were male and 15 females.

The distribution of the residency duration of the participants during the first program were as follows; $17,1 \%$ were in the first year, $31,4 \%$ in the second year, and $51,4 \%$ in the third year.

Intubation success rates were $80 \%(28 / 35)$ at the end of the first program and $100 \%(35 / 35)$ at the end of the second. Endotracheal intubation success rate of the residents after the second program was found to be $(100 \%)$ higher than the success rate of first education (80\%) which was statistically significant $\left(\chi^{2}=7.667\right.$, $\mathrm{p}=0.006)$.

The mean endotracheal intubation times of the residents who attended both programs were calculated. The mean time of successful endotracheal intubation in the first and second programs were $14.14 \pm 4.16 \mathrm{sec}$ and $8.22 \pm 3.58 \mathrm{sec}$, respectively. Intubation times in the second program were found to be significantly lower than the first $(p<0.01)$.

There was no statistically significant difference between groups among intubation success rates and years of seniority $(p>0.05)$.

\section{Discussion}

Because the majority of childhood cardiopulmonary arrests develop as a result of respiratory failure, pediatricians must be able to manage airway successfully $(2,6)$. Successful endotracheal intubation for cardiopulmonary arrest directly affects many systems, especially neurological functions of children (3). Theoretical and practical lessons about airway management are provided during the training of pediatric residency. As the number of children who need advanced airway support decreases each year, the number of patients undergoing endotracheal intubation also decreases. This situation causes the pediatric residents to have insufficient experience in airway management $(7,8)$. Today, SBE are successfully being used in pediatric residency to overcome this lack of experience $(9,10)$. This study showed that simulation-based endotracheal intubation education with highreality manikins increased intubation success and shortened intubation time.

SBE has been on the agenda for a long time in business areas such as the aviation, nuclear power industry and medical education. Simulation based advanced airway management training is frequently used because it provides a safe training environment and unlimited repetition of training (11).

Providing advanced airway support for pediatric patients, is one of the important responsibilities of pediatric specialist in our country. Therefore, gaining the ability of providing advanced airway is important for residents of pediatrics' professional 
development. In the study of Kendirli et al. (12) it was reported that the intubation success increased after training with manikins in the pediatric advanced life support course. In our study, it was also determined that the success of intubation increased as a result of simulation based endotracheal intubation education (12). These two studies were conducted in the same country. The reason why our study resulted in a similar way to the study of Kendirli et al. (12) may be that pediatric residents worked under similar conditions.

Nishisaki et al. (13) reported that simulation-based airway education did not affect endotracheal intubation success. It was noteworthy that a respiratory support team consisting of healthcare professionals in various branches was responsible for advanced airway support at their centers (13). In our country, providing advanced airway support for pediatric patients is among the primary duties of pediatric residents (12). The reason why this study's results differ from our study, may be that the advanced airway procedures were not primarily in the responsibility of residents of pediatrics in the mentioned study.

In the study conducted by Miller et al. (14) the intubation times were compared at the end of the second education that was carried out three months after the first education. When intubation times were examined at the end of these two trainings, there was no statistically significant difference. In our study, statistically significant difference was found between intubation times after first and second programs. The residents managed endotracheal intubation faster in the second program (14.14 sec vs $8.96 \mathrm{sec})$. This result may be related to the one-year interval for the second program in our study and residents might have the chance to practice entotracheal intubation on patients during this time period.

In the study of Campbell et al. (15) in which they used high and low fidelity simulators, the mean intubation time was reported to be $179 \mathrm{sec}$ with high fidelity models and $268 \mathrm{sec}$ with low fidelity models. The longer mean time in this study than our's may be due to the fact that the study was conducted on family medicine residents who had no experience of child endotracheal intubation. All of the participants in our study were residents of pediatrics. Since some of our participants were senior pediatric residents, the intubation times in our study may have been shorter than that study.

\section{Study Limitations}

Our study had some limitations. The first is that pre-test has not been performed for endotracheal intubation success before training. The second is that the factors other than education, which affect the ability of residents to perform endotracheal intubation, cannot be evaluated within a year between two training sessions. And the third is the low number of participants in both programs.

\section{Conclusion}

In our study, it was found that SBE, which were performed one year apart through high-fidelity manikins, increased the success of endotracheal intubation. It was also determined that these educations shorten the time for residents of pediatric to perform intubation. Gaining intubation skills is related to the psychomotor field of learning. The most effective method to acquire this skill in the pediatric residency process is intubation in the real patient and in case of real need. The low number of pediatric cases requiring intubation leads to the failure of every pediatric resident to use this method. For this reason, it is important to reinforce this skill by using high-fidelity simulators. More prospective, randomized controlled studies should be conducted in this area.

\section{Ethics}

Ethics Committee Approval: It was obtained from Ethics Committee of Necmettin Erbakan University Meram Faculty of Medicine Ethical Researches Non-Pharmaceuticals and Medical Devices (decision no: 2020/2502, date: 22.05.2020).

Informed Consent: Written and verbal consent was obtained from all participants for the study.

Peer-review: Externally peer-reviewed.

\section{Authorship Contributions}

Surgical and Medical Practices: A.O.K., E.T., A.Y., F.A., I.R., Concept: A.O.K., E.T., A.Y., F.A., I.R., Design: A.O.K., E.T., A.Y., F.A., İ.R., Data Collection or Processing: A.O.K., E.T., A.Y., F.A., I.R., Analysis or Interpretation: A.O.K., Literature Search: A.O.K., Writing: A.O.K.

Conflict of Interest: No conflict of interest was declared by the authors.

Financial Disclosure: The authors declared that this study received no financial support.

\section{References}

1. Hartmann ME, Cheifetz IM. Pediatric Emergencies and Resuscitation. In: Kliegmann MRM, St Geme JW, editors. Nelson Textbook of Pediatrics. 21th ed. Philadelphia, PA: Elsevier; 2020. S. 530-47.

2. Duff JP, Topjian AA, Berg MD, Chan M, Haskell SE, Joyner BL Jr, et al. 2019 American Heart Association Focused Update on Pediatric Advanced Life Support: An Update to the American Heart Association Guidelines for Cardiopulmonary Resuscitation and Emergency Cardiovascular Care. Circulation. 2019;140:904-14.

3. Sudikoff SN, Overly FL, Shapiro MJ. High-fidelity medical simulation as a technique to improve pediatric residents' emergency airway management and teamwork: a pilot study. Pediatr Emerg Care. 2009;25:651-6. 
4. Brady PJ, Simmons JM. Safety in Healthcare for Children. In: Kliegmann MRM, St Geme JW, editors. Nelson Textbook of Pediatrics. 21th ed. Philadelphia, PA: Elsevier; 2020. s. 38-45.

5. O'Donnell CP, Kamlin CO, Davis PG, Morley CJ. Endotracheal intubation attempts during neonatal resuscitation: success rates, duration, and adverse effects. Pediatrics. 2006;117:16-21.

6. Doughty CB, Kessler DO, Zuckerbraun NS, Stone KP, Reid JR, Kennedy CS, et al. Simulation in Pediatric Emergency Medicine Fellowships. Pediatrics. 2015; $136: 152-8$

7. Lin $\mathrm{Y}$, Cheng $\mathrm{A}$. The role of simulation in teaching pediatric resuscitation: current perspectives. Adv Med Educ Pract. 2015;6:239-48.

8. Gabrani A, Kojima T, Sanders RC Jr, Shenoi A, Montgomery V, Parsons SJ, et al. Downward Trend in Pediatric Resident Laryngoscopy Participation in PICUs. Pediatr Crit Care Med. 2018;19:242-50.

9. Parmekar S, Arnold JL, Anselmo C, Pammi M, Hagan J, Fernandes CJ, et al. Mind the gap: can videolaryngoscopy bridge the competency gap in neonatal endotracheal intubation among pediatric trainees? a randomized controlled study. J Perinatol. 2017;37:979-83.
10. Alyousef S, Marwa H, Alnojaidi N, Lababidi H, Bashir MS. Cumulative evaluation data: pediatric airway management simulation courses for pediatric residents. Adv Simul (Lond). 2017;2:11.

11. Kane J, Pye S, Jones A. Effectiveness of a simulation-based educational program in a pediatric cardiac intensive care unit. J Pediatr Nurs. 2011;26:287-94.

12. Kendirli T, Caltik A, Duman M, Yilmaz HL, Yildizdaș D, Boșnak M, et al. Effect of pediatric advanced life support course on pediatric residents' intubation success. Pediatr Int. 2011;53:94-9.

13. Nishisaki A, Donoghue AJ, Colborn S, Watson C, Meyer A, Brown CA 3rd, et al. Effect of just-in-time simulation training on tracheal intubation procedure safety in the pediatric intensive care unit. Anesthesiology. 2010;113:214-23.

14. Miller KA, Monuteaux MC, Aftab S, Lynn A, Hillier D, Nagler J. A Randomized Controlled Trial of a Video-Enhanced Advanced Airway Curriculum for Pediatric Residents. Acad Med. 2018;93:1858-64.

15. Campbell DM, Barozzino T, Farrugia M, Sgro M. High-fidelity simulation in neonatal resuscitation. Paediatr Child Health. 2009;14:19-23. 